\title{
Language Anxiety and Foreign Language Teaching
}

\author{
Zhang Xie, Ji Huanqi \\ College of Law and Literature, Sichuan Agricultural University Sichuan Ya'an 625014, China \\ Zhangxie163@163.com
}

Keywords: language anxiety, type, suggestion

\begin{abstract}
. language anxiety is a significant emotional factor that affects foreign language learners in the classroom and has been increasingly drawing attention in the academic field. Through the introduction of FLCAS in the experimental study on language anxiety, this paper analyzes foreign language learner's communication fear, test anxiety and negative judgment fear, and hence proposes ways to reduce and eliminate language anxiety from the perspective of teaching notions, teachers as well as learners.
\end{abstract}

\section{Introduction}

Language anxiety refers the nervous state of language learners developed in learning or using a foreign language because they have their self-esteem or self-confidence damaged as they anticipate they cannot achieve their goals. Such nervous state is often accompanied by fear. Researches on language anxiety began with the study on individuality of language learners in the 1970s. As is pointed out by $\mathrm{Li}$ Jiongying (2004), studies on individuality of language learners mainly concentrated on intelligence and learning competence while emotional elements have been seldom probed. With the development of individual psychology exemplified by Maslow's study on the hierarchy of needs and Rogers' personality theory, it has been acknowledged that it is far from enough to explain the foreign language study process only from a cognitive point of view. In fact, emotional factors in such a process grow to catch researchers' attention. The researches of Brown (1973), Krashen (1982), Gardner (1985), Steinberg \& Horwitz (1986) held that language anxiety constitutes a most important part among the emotional factors of a foreign language learner. Although language anxiety may have a positive effect, and is possible to disappear as time passes by, it is likely to have a negative effect. Oxford (1999) and Arnold (1999) thought that language anxiety varies inversely with self-confidence, study record and ability to express oneself and even becomes the largest emotional barrier in foreign language study. As Chinese researchers have fallen behind in the study of language anxiety, this paper intends to analyze language anxiety and seek effective strategies on resolving it so as to propose ways to solve the problems facing learners and promote foreign language teaching.

\section{Researches of Language Anxiety}

Language anxiety is different from the ordinary anxiety in that it usually arises from a foreign language learning situation and falls into the specific scope of contextual anxiety. Horwitz, Horwitz \& Cope (1986) pointed out that language anxiety is a type of complex apparently connected with self-consciousness, belief, emotion and behavior of a language learner in a foreign language classroom. It comes into being on account of the uniqueness of foreign language learning process. Horwitz \& Young (1991) advanced a similar notion in the book titled Language Anxiety: From Anxiety and Research to Classroom Implications, in which they stress the correlation of language anxiety and foreign language classroom and that the former definitely appears in the language learning process. Meanwhile, MacIntyre \& Gardner (1994) believed that language anxiety is due to nervousness and fear which have special bearing on foreign language context. In order to understand and evaluate the effects of language anxiety on foreign language learners, Horwitz (1986) designed a Foreign Language Classroom Anxiety Scale (FLCAS) based on students' self-report, teaching practice and a series of calculations. FLCAS consists of 33 questions, each of 
which has five choices ranging from "strongly agree”, "agree”, "not sure”, "disagree” to "strongly disagree”. Those questions are typically associated with difficulties in listening, speaking, reading and writing, speed of language processing as well as memory of foreign language. Students can decide on the one that best fits them according to their own practical situation. In the process, Horwitz applied the FLCAS to examine 75 American college students from four elementary Spanish classes, among whom 39 students were boys and others were girls. The results are as follows: firstly, language anxiety is wide-spread in foreign language classroom (at least, language anxiety is common at a college elementary foreign language course). Secondly, students suffering from language anxiety can be identified and their anxieties have quite a lot in common. Thirdly, students with high language anxiety are usually afraid to speak the foreign language in class.

Since the advent of FLCAS, it has been applied to different foreign language teaching classes. Satio, Horwitz \& Garza (1999) surveyed 383 American college students who just started their French, Japanese and Russian classes and found that students' language anxiety increased with the intensity of foreign language reading. Cheng, Horwitz \& Schallert (1999) examined 433 Taiwanese English majors and revealed that language anxiety varied conversely with students' oral and writing performance. Still, Elkhafaifi (2005) conducted a survey among 233 American college students studying Arabic and disclosed that language anxiety in listening comprehension can produce an obviously negative effect on their language study. All those above-mentioned researches almost reach the same conclusion: language anxiety can affect the study in a foreign language class and varies inversely with students’ performance.

\section{Types of Language Anxiety}

Anxiety has been classified by Spielberger (1983) into 3 major types as: 1) trait anxiety, a characteristic of a learner's personality, 2) state anxiety, apprehension experienced at a definite situation at a particular moment, and 3) situation-specific anxiety, one aroused by a particular kind of situation. In the eyes of Spielberger, anxiety can be either facilitative or debilitative. But, for language anxiety, scholars like Horwitz, MacIntyre \& Gardner usually regard it as situation-specific psychological tension that language learners experience when they perform a learning task. This kind of mental block has been claimed by many people against learning a foreign language. A modified Horwitz et al's (1986) FLCAS divided language anxiety into three major types, which are communication apprehension, test anxiety and fear of negative evaluation.

Communication apprehension is defined as a kind of shyness or fear when language learners anticipate communicating with others or is in the middle of such communication. The major reason is that they are worried about being unable to appropriately use the target language to express themselves. Learners may find it difficult to complete the tasks like making up conversation in a group or speaking before the whole class and they may also feel it hard to understand or copy what other people say. As a result, learners are likely to get frightened or become anxious in receiving information. They will surely have a hard time talking to others. Learners tend to use a limited range of knowledge to communicate with others, and frequently fail to understand what their partners say and make themselves understood as well. Meanwhile, learners usually make up conversation about a chosen topic and are unable to take a good control of the situation where they are constantly followed by close attention from their teacher and other students. Therefore, when communication apprehension happens, learners are very likely to withdraw themselves and not to draw others' attention. As is demonstrated in Foss \& Reitzel (1988) research, if there exists communication apprehension in the class of English as a foreign language, it seems to pose a block against students' mastery of the language.

Test Anxiety refers to a type of anxiety stemming from a fear of failure or worries about being unable to do well in a test. This has much to do with the frequent testing and examinations in the language classroom. Test anxiety is usually triggered by a deficiency of study skills because tests about the learners' language competence is almost conducted at any moment and learners are prone to make mistakes which always put them under constant pressure. As often happens, learners would be aware afterward that they knew the correct answer but failed to give it because of nervousness. If 
they are always conscious of the mistakes they made, which in fact could have been overcome, their test anxiety will become worse and they are likely to make more similar mistakes. Although some learners try to double their efforts to make up for those mistakes, they still fail to improve their performance. Consequently, their study effectiveness is bound to be affected. The research conducted by Aidia (1994) indicates that learners who have gone through too many failures in tests would have their test anxiety so high that they always hold negative thoughts about themselves before or in the middle of the test. As a result, their performance in tests goes from bad to worse.

Fear of negative evaluation is third type of anxiety which is closely connected with foreign language learning. It is defined as apprehension about the expectation that others would make a negative evaluation about oneself. To some degree, fear of negative evaluation is similar to test anxiety, but is broader in scope because it is not limited to tests only. It can appear at any moment in class. Learners are often evaluated by their teacher in class, but are also evaluated by other learners as well. It is noteworthy to point out that learners are more sensitive to the evaluations by their peer, whether such evaluations are true or just imaginary. If learners are overly concerned about others' opinion about themselves, they tend to reduce the possible negative evaluations to the lowest point, and they may also have low expectations about themselves. Psychologically speaking, if they keep doing this, they are likely to have their self-confidence and self-esteem damaged. Moreover, the research conducted by Cheng, Horwitz \& Schallert (1999) found that it is easy for Taiwanese college students to have language anxiety in the class if they tend to experience fear of negative evaluation and worries about negative evaluation in writing has much to do with language anxiety in the classroom.

\section{Pedagogical Suggestions}

Although language anxiety can bring about negative effects on both foreign language learning and teaching, it can be reduced or even overcome. Horwitz (1986) offered two suggestions: first, foreign language teachers shall properly deal with various factors that cause language anxiety. Second, foreign language teachers shall reduce the pressure in the classroom. Whichever approach is taken, Horwitz stressed, teachers must acknowledge the existence of language anxiety among the learners. Nevertheless, the above-mentioned suggestions just serve as guiding lines for the reducing language anxieties, and are too general to be put into practice. Language anxiety can be reduced or even eliminated through the following ways:

Firstly, both teachers and learners shall take a new approach to the foreign language class. Traditional language teaching concept stresses that teachers shall dominate the class and learners are supposed to center around the teacher. As a result, learners are usually led by the teacher and passively absorb what is being taught, and such an approach creates a situation where language anxiety is likely to be induced, hence posing a great barrier to both teaching and learning in the classroom. With the new trend of teaching method, foreign language teaching shall center on the learners rather than the teachers. Teachers must get to know it is learners that are supposed to actively participate in mastering and accumulating language knowledge while teachers' role is to focus on guiding and promoting such a process.

Secondly, foreign language teachers are supposed to create a low-pressure learning environment. From the perspective of humanistic psychology, learning is regarded as an integration of cognition and emotion. Teachers and learners mutually understand and communicate with each other in the learning process. Teachers can greatly help learners reduce anxiety if they are described as "helpful”, "encouraging", "friendly", or "understanding”. Removing the teachers' role from the center of a foreign language class can make the language learners realize that such an approach is "encouraging" when they get to know that they are expected to take the initiative to master the language. Teachers will be considered to be very "helpful” if they guide learners' initiative toward attaining mastery of the language. This is particularly the case with East Asian classes where teachers have long developed a sense of authority since ancient time. They have long been considered to be knowledgeable and seem to be capable of everything. Thus, learners are often supposed to be completely submissive and should do whatever they are told. Such stereotyped 
images tend to make learners take a passive approach in class and are always waiting for teachers to give them instructions. Meanwhile, for language teachers, a smiling face can always put learners at ease and a good sense of humor will lighten up a classroom. Teachers shall also remove habit of rushing to correct learners whenever they make a mistake, be it big or small, as it is very common for them to make mistakes in the class and they may even stumble over the same mistakes over and over again. Teachers' frequent corrections or even harsh feedbacks will greatly increase learners' anxiety in class. Such approaches can make learners perceive teachers as "friendly" and "understanding" and can also help to reduce considerably anxiety of learners. In addition, Li Jiongying (2007) thought that it is necessary for foreign language teachers to learn and practice some teaching strategies that can reduce language anxiety such as the silent way, community language learning and communicative language teaching so that teachers can adopt class activities that better fit the diverse needs of learners so as to create a good foreign language learning environment.

Thirdly, language learners shall strengthen their self-esteem and self-confidence. It is commonly agreed that learning is closely related to the foregoing two factors. Heyde (1979) once conducted a survey about the connection between self-esteem and foreign language learning, and found that self-esteem varies with foreign language performance and particularly with oral competence. Language anxiety differs greatly between language learners with high self-esteem and those with low self-esteem, that is, it is quite easy for the latter to experience language anxiety. Meanwhile, Cheng, Horwitz \& Schallert (1999) believed that some language learners are afraid of communicating in target language, some are concerned about making mistakes and still others are worried about the negative evaluations about themselves made by others. They all are actually lacking in self-confidence. In order to strengthen language learners' self-esteem and self-confidence, teachers shall encourage and trust learners, giving more praises than corrections or critical comments. They shall help learners form a correct attitude toward mistakes and let them know it is common and understandable to make mistakes in class or fail occasionally in test. On the other hand, learners must learn to recognize and share their language anxieties. It is important for them to be able to recognize their own feelings and learn that it is normal and natural for them to experience language anxiety and that they are not the only ones suffering such feelings. Thus they can develop a mutual trust by which they can learn the foreign language in a cooperative way without being bothered by the fear of negative evaluations from their peers. Consequently, learners have their self-esteem and self-confidence protected by a large extent in class.

\section{References}

[1] Brown, H. D. Affective variables in second language acquisition [J]. Language Learning, 1973, (25):153-161.

[2] Krashen, S. D. Principles and practice in second language acquisition [M]. Oxford: Pergamon, 1982.

[3] Gardner, R. Social Psychology and Second Language Learning: The role of attitude and motivation [M]. London: Edward Arnold, 1985.

[4] Steinberg, F. \& Horwitz. The effect of induced anxiety on the denotative and interpretative content of second language speech [J]. TESOL Quarterly, 1986, (20):131-136.

[5] Oxford, R. L. Anxiety and the language learner: New insight[A]//Arnold. Affect in Language Learning[C]. Cambridge University Press, 1999.

[6] Arnold, J. \& H. J. Brown. Introduction [A]//J. Arnold. Affect in Language Learning[C]. Cambridge University Press, 1999.

[7] Horwitz, E., M. Horwitz \& J. Cope. Foreign language classroom anxiety[J]. Modern Language Journal, 1986, (70):125-132. 
[8] MacIntyre, P. \& R. Gardner. The subtle effects of language anxiety on cognitive processing in the second language [J]. Language Learning, 1994, (44):283-305.

[9] Saito, Y., E. K. Horwitz \& T. J. Garza. Foreign language reading anxiety[J]. Modern Language Journal, 1999, (83):202-218.

[10] Cheng, Y-S, E. K. Horwitz \& D. L. Schallert Language anxiety: differentiating writing and speaking components [ J]. Language Learning, 1999, (49):204-217.

[11] Elkhafaifi, H. Listening comprehension and anxiety in the Arabic language classroom. Modern Language Journal, 2005, (89):206-220.

[12] Foss, K. A. \& A. C. Reitzel. A relational model for managing second language learning anxiety [J]. TESOL Quarterly, 1988, (22):437-454.

[13] Spielberger, C. D. Manual for the state-trait anxiety inventory STAI, Palo Alto, Ca: Consulting Psychologists Press, 1983.

[14] Aidia, Y. Examination of Horwitz, Horwitz, and Cope's construct of foreign language anxiety: The case of students of Japanese [ J]. Modern Language Journal, 1994, (18):155-168.

[15] Li Jiongying. Psychological and neurobiological analysis of foreign language learning anxiety[ J]. Journal of Tianjin Foreign Studies University, 2004, (4): 46-51.

[16] Li Jiongying. Second language/foreign language anxiety research abroad over 30 years [ J]. Foreign Language Teaching Abroad, 2007,(4):57-63. 